\title{
Da classificação de cargos
}

Alguns Aspectos Problemáticos Ligados à Aprovação e à Administração de um Plano de Classificação de Cargos no Serviço Público Federal Brasileiro Hodierno.

\section{Cornélio Octavio Pinheiro Pimenta}

\section{INTRODUÇÃO}

\section{$\mathrm{P}$}

ROPOMO-NOS, nesta tese, mostrar os atuais empecilhos de tôda ordem surgidos na fase de aprovação que dificultam a correta implantação e administração de um Plano de Classificação de Cargos no serviço público federal na época hodierna, e, através dêste conhecimento e do exame crítico, mas construtivo, dos obstáculos, procuramos mais alcançar as verdadeiras causas dêste estado de coisas.

Alcançadas as causas, poderemos, então, procurar afastá-las, apontando soluções que visem a purificar o uso dêste instrumento tão necessário, básico mesmo, não só a uma sadia e racional politica de administração de pessoal como também a uma melhor organização das estruturas administrativas governamentais.

Utilizando-se melhor o instrumento mediante a adoção das soluções aventadas, teremos, sem desprezarmos a importância de tôdas as demais funções da administração de pessoal, dado um grande passo no sentido de alcançarmos os superiores objetivos de uma racional política de pessoal, ou seja proporcionar a todos os servidores real satisfação no trabalho, traduzida em elevado moral, eficiência, entusiasmo, lealdade e orgulho em servir ao Govêrno.

\section{DESENVOLVIMENTO DO TEMA}

Comecemos por fixar o conceito, os objetivos e a importância de uma adequada classificação de cargos.

"Classificação é a separação dos cargos, segundo processo adequadamente escolhido, para se colocar em um mesmo grupo, 
os que apresentarem caracteristicas semelhantes e, em outros, os que mostrarem particularidades diferentes".

E "em têrmos gerais, o objetivo de uma classificação de tarefas é lançar as bases para um equitativo tratamento dos servidores, através de definição correta, agrupamento ordenado e imparcial avaliação dos cargos". (2)

Com referência à importância da classificação de cargos, os estudiosos do assunto são unânimes em afirmar a extraordinária valia dêste instrumento administrativo.

"Estruturada com base na análise das tarefas dos cargos e, consequientemente, na competência fixada e nas responsabilidades impostas aos ocupantes, impõe-se a classificação como instrumento indispensável ao encaminhamento dos aspectos técnicos da administração de pessoal, bem como de vários problemas de organização. Não existe uma só fase do processo administrativo em que não se possa apontar, direta ou indiretamente, a classificação como meio idôneo para oferecer soluções equilibradas. Não se restringe ela ao campo de pessoal. Penetra, também, no problema mesmo da estrutura, extravasa-se para o aspecto orçamentário e vai impor-se como elemento indispensável à uniformização da terminologia entre os vários departamentos, aumentando a facilidade de comunicação".

Por sua vez, diz-nos BARUCH que é "objetivo da classifica ção de cargos obter e manter esta relação e servir neste e em outros sentidos como principal instrumento para a administração de pessoal". (4) WHITE assinala que "a classificação de cargos é a única base capaz de sustentar um seguro programa de pessoal". (5)

Segundo Pfiffner a clasificação de cargos é "a chave de um correto programa de pessoal" (6) e, para BROOCKE GRAVES, é "a base de tôdas as etapas das atividades de pessoal". (7)

(1) AdAlmo de ARAújo ANDRAde - Diretrizes para Classificação de Cargos. Instituto de Ciências Econômicas, Politicas e Sociais de Minas Gerais (ICEPS) - Bela Horizonte - 1960 - pág. 49.

(2) Harvey Walker - Public Administration in the United States. Farrar \& Rinehart Incorp., pág. 159.

(3) Adalmo de Araújo Andrade, obra citada, página 26.

(4) Ismar Baruch - Basic Aspects of position classification. Reading in Personnel Administration. Civil Service Assembly of the United States and Canada. EE. UU. 1942 - páginas 27-29.

(5) LEONARD D. White - Introduction to the study of public adminis. tration. 3th. edition. The Mac Millan Comp. New York - 1949 - páginas
369-371.

(6) JOHN PFIFFner - Public Administration. Revised edition. Ronal Press Company. New York. 1946 - página 283.

(7) W. Brooke Graves - Public Administration in a democratic society. D. C. Health and Company. Boston, 1950 - página 134. 
Finalmente, para PAulo Poppe de Figueiredo, ela é "a estrutura indispensável sôbre a qual se deve levantar uma administração de pessoal em bases racionais" (8) e, segundo NAZARÉ DIAS, "a classificação de cargos assume papel relevante, manifesta em sua plenitude, seu valor inestimável de instrumento útil, de peça imprescindivel na politica do pessoal da organização". (9)

Examinada a importância da classificação de cargos para qualquer administração, pública ou particular, que deseje operar em bases racionais, vejamos, com relação ao tema, alguns problemas ligados às fases de aprovação e administração do atual Plano de Classificação de Cargos do serviço público federal brasileiro. O fato de não nos ocuparmos das demais fases do Plano, ou seja, as de preparação e implantação, não significa inexistirem problemas intrincados com referência a êstes momentos do instrumento; ao contrário, por existirem é que nossa tese se limitará à tarefa de encontrar soluções apenas para alguns problemas ligados à fase de aprovação; caso contrário, teríamos que nos alongar demasiadamente ou escrever outras teses.

A preferência se prende ao fato de que as fases de preparação, em nosso atual regime político, são cometidas ao D.A.S.P., órgão central de pessoal do serviço público federal brasileiro, o qual se acha tècnicamente preparado para tarefa de tanta complexidade e responsabilidade.

Com relação à fase de aprovação, o Plano de Classificação de Cargos tem que ser submetido à apreciação do Poder Legislativo. E a Lei $n^{\circ} 3.780$, de 12-7-60, que aprovou o $1^{\circ}$ Plano de Classificação de Cargos no serviço público federal brasileiro bem comprova a magnitude dos problemas que surgem. Bastaria fôsse comparada com o anteprojeto de lei preparado no D.A.S.P. e enviado ao Congresso pelo Presidente da República para se verem, claramente, as alterações e deturpações por que passou, desvirtuando-se em larga escala o alto sentido de que era portador: o de introduzir no serviço público federal os sãos princípios filosóficos da imparcialidade e do mérito no campo da administração de pessoal.

"O ato legislativo - escreve NAzARÉ DIAS, deve limitar-se ao estritamente essencial de modo a não invadir ou perturbar a esfera estritamente regular, de competência do Executivo". E mais adiante prossegue: "... o que ocorre é a invasão, pelo

(8) Usos e vantagens da classif cação de cargos. Revista do Serviço público. Vol. II, $\mathrm{n}^{\circ} 2$. Maio de 1952 - página 11.

(9) J. DE Nazaré T. Dias - Classificação de Cargos. Caderno de Administração Pública n 27. Fundaçăo Getúlio Vargas. Rio de Janeiro, 1955 - página 4. 
Legislativo, da esfera de competência do Executivo. O poder Regulamentar, inquestionàvelmente do Executivo, não é respeitado. O resultado é que as leis perdem, cada vez mais, seu teor legal, sua majestade, para descerem à planura da regulamentação, com evidente desprestígio para a tarefa legislativa e enormes prejuizos à boa marcha da administração". (10)

O retrato nos parece perfeito. Além das deturpações ocorridas com o Plano elaborado pelo D.A.S.P., o Congresso ainda cerceou o Poder Executivo, dificultando-lhe a possibilidade de aprefeiçoar o atual estado de coisas através da fase de adminis. tração do Plano.

A Ciência da Administração é essencialmente dinâmica e progressista. O Direito Administrativo, porém, não tem acompanhado a evolução da Ciência da Administração, permanecendo, no Brasil, prêso a sistemas e procedimentos jurídicos obsoletos e estáticos, preocupado com minúcias, rígido, inflexível e excessivamente conservador, fomentando a administração rotineira que se apresenta incompativel com os anseios coletivos de desenvolvimento sócio-econômico e principalmente ético do País, ao invés de criar condições que possibilitem sua erradicação.

Aprisiona o Poder Executivo em um esquema jurídico rígido, esquecido de que a política e a sua execução são fases de um só processo: o de administrar. Devem, pois os Poderes Legislativo e Executivo agir harmoniosamente como, aliás, preceitua a nossa Constituição.

E' preciso que o Poder Legislativo permita ao Poder Executivo trazer o Plano “... sempre atualizado, não permitindo a permanência de um enquadramento quando as tarefas de um cargo tenham sofrido mudança, com alteração, também, na atribuição e responsabilidade do ocupante" (11); "o que é importante, como se nota, é não fazer do plano nada de definitivo, senão um instrumento atualizado, de modo a poder estar sempre conjugado com a realidade, como é do interêsse da administração e da finalidade da classificação". (12)

Ou, no dizer da United States Civil Service Comission, presidida por ISMAR BARUCH, "um plano de classificação de cargos não é algo que se estabeleça em determinado momento para permanecer imutável dai em diante. Ao contrário, é êle dinâmico e cresce de acôrdo com as tendências do próprio serviço". (13)

(10) J. de NAzaré Dias - obra citada - página 18.

(11) Adalmo de Araújo Andrade - obra citada - página 114.

(12) Adalmo de Araújo Andrade - obra citada - página 115.

(13) Relatório da Com'ssão de Planos de Classificação de Cargos e Remuneração da Ex-Civil Service Assembly of the United States and Canada 
Surge, então, o problema: como manter o Plano sempre atualizado; como realizar constantemente periódicas revisões; como tirar sucessivas fotografias dos diversos órgãos governamentais de modo que se possam suprimir, alterar ou criar cargos e, desta forma trazer o Plano sempre ajustado à realidade dos fatos que ocorram nas repartições, se o Poder Executivo, através de seu órgão central em administração de classificação de cargos, se encontra aprisionado pelo Poder Legislativo mediante leis rígidas e inflexíveis?

“Após a implantação do nôvo sistema de classificação, respeitadas as exceções previstas nesta lei, será responsabilizado o Chefe de Serviço, sob pena de demissão, ou destituição de função, que conferir a qualquer servidor atribuição diversa da pertinente à classe a que pertence. Em caso algum poderá tal fato acarretar a reclassificação do funcionário ou a sua readaptação; determinará apenas a correção da irregularidade, mediante retôrno do funcionário às atribuições de seu cargo" - eis o texto do artigo 47 da Lei $n^{9} 3.780$, de 12-7-60, que dispõe sôbre a classificação de cargos do Serviço Civil do Poder Executivo.

A nós, nos parece impossivel que o administrador progressista, desejoso, com sinceridade, de acompanhar a evolução da técnica administrativa, possa evitar o desvio de funções: estas se alteram, se modificam com o aperfeiçoamento dos métodos de trabalho. Fugir deliberadamente ao progresso administrativo por aprisionamento a artigos de lei inflexiveis seria a consagração da rotina e do obsoletismo.

Poder-se-ia objetar ao argumento supra dizendo-se:

a) O Poder Legislativo não confia nos homens que dirigem os órgãos governamentais do Poder Executivo, e teme que cometam protecionismos se lhes fôr dada uma lei que permita uma maior soma de poder discricionário em matéria de administração de pessoal.

b) $\mathrm{O}$ artigo 47 da Lei $n^{2} 3.780-60$, acima citado, não impossibilita a evolução das atribuições e conseqüentemente das responsabilidades dos cargos, mas tão somente visa a impedir que servidores sejam desviados para funções diversas das de seu cargo, ocasionando necessidade de novas readaptações, as quais, em essência, visariam a proteger determinados servidores em detrimento de outros.

(atual Public Personnel Association) Presidente Ismar Baruch - "Classificaçễo de Cargos no Serviço Público (fascículo I)" - Tradução do D.A.S.P. - 1959 - pág. 79. 
Ao que retrucariamos, dizendo:

a) A desconfiança gera a desconfiança. Se os dirigentes de órgãos governamentais sentem que o Poder Legislativo lhes dificulta a ação de administrar, por nêles não confiar, motivos de ordem psicológica podem levá-los a procurar brechas na lei, mediante o uso de sutilezas jurídicas, reagindo à opressão e à coação legal.

Acresce dizer que falecerá autoridade moral ao Congresso para tentar, através da lei, evitar protecionismos por parte dos agentes do Poder Executivo se, ao votar o anteprojeto de lei que o Poder Executivo lhe enviar em bases técnicas e racionais, alterar-lhe as normas, deturpar-lhe o sentido e proteger determinadas classes de servidores, quer elevando seus niveis, sem razões de ordem técnica e com reflexos na faixa salarial, quer excluindo-os da sistemática do Plano.

Se o Congresso desejar evitar abusos, melhor agirá autopoliciando-se do que inserindo artigos na Lei que, além de contraproducentes - por motivos psicológicos, levem o Direito Administrativo a entravar a Ciência da Administração e a se manter obsoleto e ultrapassado. Agindo assim, o Congresso desprestigia o Direito Administrativo, afastando-o da Ciência da Administração ao invés de procurar dinamizá-lo e adaptá-lo à continua evolução social e administrativa do Pais.

b) Em parte já retrucamos a êste ponto com o acima dito. Acrescentaríamos apenas que as atribuições e responsabilidades de certos cargos, pela evolução da administração, podem vir a se alterar de tal forma que do cargo antigo o nôvo só conserve a terminologia, operando-se, assim, um autêntico desvio de funções, não para cargo de outra denominação por motivos protecionistas, mas apenas por desaparição das antigas funções e por questões de progresso técnico dentro dos órgãos governamentais.

Expostos os problemas que surgem nas fases de aprovação e de administração do atual Plano de Classificação de Cargos do serviço público federal, qual a solução ou soluções que aventamos? E' o que veremos no item seguinte.

\section{CONCLUSÕES}

Nossas conclusões se assentam na premissa de que, para atender aos objetivos e aos limites da presente tese, damos como não discutivel o regime de democracia representativa e da tripartição dos Podêres da União - Legislativo, Executivo e Judiciário "independentes e harmônicos entre si" conforme dispõem os arti- 
gos $1^{\circ}$ e $36^{\circ}$ da Constituição dos Estados Unidos do Brasil, em vigor.

\section{Concluiriamos, então:}

1) Em face do exposto no item II, números 5 e 6 , da presente tese, defendemos, em matéria de Classificação de Cargos, a revisão do atual Plano pelo Poder Executivo, que o purificaria, eliminando protecionismos dispensados a certas classes, estendendo a sistemática do Plano a classes que ainda não abrange, bem como afastando os atuais entraves que dificultam a sua boa administração e possibilitando seja mantido sempre atualizado e dinâmico. Esta revisão poderia vir a ser efetuada mediante a delegação de Podêres que seria concedida pelo Legislativo ao Executivo, e encontra amparo legal no artigo 22 e seu parágrafo único, do Ato Adicional à Constituição dos Estados Unidos do Brasil, promulgado pelo Congresso Nacional em 2-9-61, que transcrevemos:

"Art. 22. Poder-se-á complementar a organização do sistema parlamentar de govêrno ora instituido, mediante leis votadas nas duas Casas do Congresso Nacional, pela maioria absoluta de seus membros.

Parágrafo único. A legislação delegada poderá ser admitida por lei votada na forma dêste artigo".

29) Obtida que fôsse a legislação delegada e aperfeiçoado o atual Plano de Classificação de Cargos, assumiria real importância a sua continua administração, conforme expusemos no item II, $\mathrm{n}^{2} 5$, do presente trabalho. No Brasil, de conformidade com os artigos 36 e 39 da Lei $n^{\circ} 3.780-60$, foram instituidas no D.A.S.P. uma Comissão de Classificação de Cargos e uma Divisão de Classificação de Cargos, cabendo à primeira, entre outras atribuições, a de propugnar pelo aperfeiçoamento da atual lei (vide art. 37 item II) e à segunda, além de outras competências, a de "realizar análise e estudos nos Ministérios e Órgãos subordinados ao Presidente da República, indispensáveis aos esclarecimentos dos pedidos de criação, alteração, extinção, supressão ou transferência de cargos ou funções", conforme dispõe o artigo 40, item V da Lei $n^{\circ}$ 3.780-60. Concluiriamos, então, que, existindo os órgãos capazes de administrar o Plano, restaria prestigiá-los aparelhando-os financeira, humana e materialmente a fim de que possam manter o Plano constantemente atualizado e ajustado à realidade.

3.) Finalmente, concluimos afirmando que, sendo a administração de pessoal um todo, divisivel em funções e técnicas apenas por questões didáticas ou de divisão do trabalho, ter-se-ia 
de aperfeiçoar, também, o Plano de Remuneração, a Seleção, o Treinamento, a avaliação de eficiência, a escolha de chefias, etc., mediante a introdução, no serviço público federal, dos princípios filosóficos da moderna administração do pessoal, ou seja: mérito, imparcialidade, neutralidade politico-partidária e anonimato.

Só, então, teremos realmente rompido a barreira do subdesenvolvimento neste país, não apenas através do progresso econômico, mas, principalmente, mediante o aperfeiçoamento ético de homem brasileiro.

\section{BIBLIOGRAFIA}

1. Adalmo de Araújo Andrade - Diretrizes para Classificação de Cargos. Instituto de Ciências Econômicas, Politicas e Sociais de Minas Gerais (ICEPS) - Belo Horizonte.

2. HaRvey WalKer - Public Administzation in the United States - Farrar \& Rinehart Incorp.

3. Ismar Baruch - Basic Aspects of position classification - Readings in Public Personnel Administration - Civil Service Assembly of the United States and Canada - EE.UU. - 1942.

4. John H. PFiffNer - Public Administration Revised - edition - Ronal Press Company - New York - 1946.

5. José de Nazaré T. Dias - Classificicação de Cargos - Caderno de Adeministração Pública n ${ }^{\circ} 27$ - Fundação Getúlio Vargas - Rio de Janeiro - 1955.

6. LeONARD D. White - Introduction to the Study of public administration - 3th. edition - The Mac Millan Company - New York - 1949.

7. PAULO POPPE DE FiguFiRedo - Usos e vantagens da classificação de cargos - Revista do Serviço Público - Vol. II, n² 2 - maio de 1952.

8. W. Booke Graves - Public Administration in a democratic society D. C. Health and Company - Boston - 1950 . 